\title{
A Novel Rose Hip Preparation with Enhanced Anti-Inflammatory and Chondroprotective Effects
}

\author{
Joseph Schwager, Nathalie Richard, Rotraut Schoop, and Swen Wolfram \\ DSM Nutritional Products Ltd., Department of Human Nutrition \& Health, P.O. Box 2676, 4002 Basel, Switzerland \\ Correspondence should be addressed to Joseph Schwager; joseph.schwager@dsm.com
}

Received 19 June 2014; Revised 25 August 2014; Accepted 9 September 2014; Published 13 October 2014

Academic Editor: Tânia Silvia Fröde

Copyright (C) 2014 Joseph Schwager et al. This is an open access article distributed under the Creative Commons Attribution License, which permits unrestricted use, distribution, and reproduction in any medium, provided the original work is properly cited.

Rose hip powder (RHP) alleviates osteoarthritis (OA) due to its anti-inflammatory and cartilage-protective properties. Substances contained in RHP might contribute to its clinical efficacy. The activity of two RHP (i.e., RH-A, from the whole fruit, RH-B, from fruits without seeds) was investigated in human peripheral blood leukocytes (PBL) and primary chondrocytes (NHAC-kn). RH-A and RH-B diminished the secretion of chemokines and cytokines in LPS/IFN- $\gamma$-activated PBL, including CCL5/RANTES, CXCL10/IP-10, interleukin- (IL-) 6, and IL-12. Most effects were transcriptional, since gene expression levels were significantly influenced by RH-A and RH-B. In IL-1 $\beta$ treated normal chondrocytes (NHAC-kn), both RH preparations reduced the expression of matrix metalloproteinase- (MMP-) 1, MMP-3, and MMP-13 and ADAMTS-4. These changes are associated with diminished inflammatory damage or cartilage erosion. Principal component analysis revealed that (1) RH-A and RH-B modified a large pattern of biomarkers, and (2) RH-B outperformed RH-A. Furthermore, RH-B contained more chondroprotective and anti-inflammatory constituents than RH-A. Thus, RHP contributed to restore cellular homeostasis in PBL and chondrocytes. RH preparations from fruits without seeds are thus expected to have an improved OA-preventive or OA-therapeutic profile, as subsequently shown in a related clinical trial.

\section{Introduction}

Osteoarthritis (OA) reflects the degradation and erosion of the extracellular matrix (ECM) and the subsequent narrowing of space in joints. The changes in ECM structure are due to the activation of enzymatic systems, that is, matrix metalloproteinase (MMPs) and aggrecanase in chondrocytes and synoviocytes $[1,2]$. The proinflammatory interleukin- (IL-) $1 \beta$ has a key role in inducing the OA phenotype in chondrocytes [3]. Likewise, nitric oxide (NO) production also correlates with pathophysiological changes in chondrocytes [4-8]. IL$1 \beta$-activated chondrocytes produce a variety of chemokines [9-12]; this might reflect the implication of cell recruitment during inflammatory processes in OA diseases.

Natural substances reportedly attenuate or delay the onset and progression of OA. Glucosamine and chondroitin have been the most promising substances so far identified, although their effectiveness is a matter of debate. Clinical studies have demonstrated a beneficial effect of rose hip powder (RHP) in the treatment of OA [13-15] (for reviews see $[16,17])$. One of its constituents, galacto-lipid (2S)-1, 2-di-O-[(9Z, 12Z, 15Z)-octadeca-9, 12, 15-trienoyl]-3-O- $\beta$ D-galacto-pyranosyl glycerol (GLGPG), has been found to inhibit chemotaxis of neutrophils $[13,14]$ and thus could impair pathophysiological cell recruitment to OA lesions. Other RHP constituents such as ascorbic acid, polyphenols, flavonoids, and unsaturated fatty acids might contribute to alleviate OA mainly via their anti-inflammatory properties. Indeed, RHP extracts and unsaturated fatty acids inhibited cyclooxygenase- (COX-) 1 and COX-2 activity $[18,19]$ and associated $\mathrm{PGE}_{2}$ production [20]. In a previous in vitro study, the multiple effects of RHP on the production of inflammatory mediators by peripheral blood leukocyte and anabolic and catabolic processes in chondrocytes have been described [20]. The current study aimed at the identification of biological activities of different parts of the rose hip fruit and an improved use of rose hip preparations in the management of OA conditions. 


\section{Materials and Methods}

2.1. Rose Hip Preparations and Reagents. RHP was prepared from Rosa canina and provided by Axellus, Ishøj, Denmark; RH-A consists of dried rose hip powder as described previously [20]; RH-B was prepared from dried rose hip, where the seeds had been removed before the preparation of the powder. The contents in main constituents (see Table 1) have been measured by standard procedures implemented at the Analytical Research Center, DSM Nutritional Products, Kaiseraugst (Switzerland). Briefly, betulinic acid, oleanolic acid, and ursolic acid were determined according to validated in-house methods (available on request); vitamin C and vitamin E were analyzed according to official methods EN14130 and EN12822, respectively; linoleic acid, EPA, and DHA were measured according to the official method of ISO 12966-2. RHP solutions were prepared in DMSO and added to the culture medium concomitantly with the stimulating agent. E. coli lipopolysaccharide (LPS, serotype 055:B5) and fetal bovine serum (FBS) were from Sigma/Aldrich (Saint-Louis, MO). RPMI 1640, DMEM, 2-mercaptoethanol, and MEM nonessential amino acids (NEAA) were from Invitrogen (Carlsbad, CA). Human IL- $1 \beta$ and recombinant interferon- $\gamma$ $(\mathrm{IFN}-\gamma)$ were from PeproTech EC (London, UK).

2.2. Cell Culture. Human peripheral blood leukocytes (PBL) and primary chondrocytes from healthy individuals have been cultured and treated with inflammatory stimuli as described [20-22]. Human primary cell culture protocols and in vitro peripheral blood leukocyte experiments were approved by the Swiss Federal Office of Public Health (no. A050573/2) and the Ethical Commission of the Kanton Aargau, Switzerland. PBL were obtained from healthy donors. PBL (at $8 \times 10^{6}$ viable cells $/ \mathrm{mL}$ ) were cultured for $12-$ $24 \mathrm{~h}$ in phenol-red free RPMI 1640 (containing 0.25\% FBS, $0.1 \mathrm{mM}$ NEAA, $50 \mathrm{U} / \mathrm{mL}$ penicillin, $50 \mu \mathrm{g} / \mathrm{mL}$ streptomycin, and $50 \mu \mathrm{M}$ 2-mercaptoethanol) and stimulated with LPS $(100 \mathrm{ng} / \mathrm{mL})$ and IFN- $\gamma(20 \mathrm{U} / \mathrm{mL})$ with graded amounts of test substances. Normal human articular chondrocytes from knee (NHAC-kn) were seeded into 6 -well plates at $0.5 \times 10^{6}$ cells per well and, where indicated, activated with $10 \mathrm{ng} / \mathrm{mL}$ IL- $1 \beta$ in supplemented CBM (Lonza, Walkersville, MD) in the presence of graded amounts of test compounds for $4 \mathrm{~h}$. In all cell cultures, vehicle (i.e., DMSO) was included at $0.5 \%$ final concentration.

For molecular analysis, NHAC-kn cells and PBLs were lysed in RLT buffer (Qiagen, Hilden, Germany) after 4 and $12 \mathrm{~h}$ of culture, respectively, and total RNA was extracted. For the analysis of secreted mediators and proteins, PBLs were cultured for $24 \mathrm{~h}$; supernatants were collected and stored at $-80^{\circ} \mathrm{C}$ until use for analysis.

2.3. RNA Isolation, cDNA Synthesis, and RT-PCR. The isolation of total RNA, synthesis of cDNA and quantitative RTPCR has been performed as detailed before [20].

2.4. Multiparametric Analysis of Cytokines, Chemokines, and Interleukins. Multiparametric kits were purchased from
TABLE 1: Constituents of RH-A and RH-B.

\begin{tabular}{lcc}
\hline Constituent $[\mathrm{mg} / \mathrm{kg}]$ & $\begin{array}{c}\text { RH-A } \\
\text { (with seeds) }\end{array}$ & $\begin{array}{c}\text { RH-B } \\
\text { (without seeds) }\end{array}$ \\
\hline GLGPG $^{1}$ & 114 & 210 \\
MGDG $^{2}$ & 71 & 120 \\
DGDG $^{3}$ & 1220 & 1900 \\
Betulinic acid $^{4}$ & 662 & 1078 \\
Betulinic, oleanolic, and ursolic & 1060 & 1711 \\
acid & 3146 & 3182 \\
Vitamin C & 129 & 212 \\
Vitamin E & 190 & 250 \\
Total carotenoids & 36 & 36 \\
$\quad \beta$-Carotene & 89 & 137 \\
$\quad$ Lycopene & 32810 & 7360 \\
Total fatty acid & 16390 & 2230 \\
$\quad$ Linoleic acid & $<$ LOD & 80 \\
EPA & $<$ LOD $^{5}$ & 60 \\
DHA &
\end{tabular}

${ }^{1}$ Galacto-lipid (2S)-1, 2-di-O-[(9Z, 12Z, 15Z)-octadeca-9, 12, 15-trienoyl]-3$\mathrm{O}-\beta$-D-galactopyranosyl glycerol.

${ }^{2}$ Mono-galactosyl diglyceride.

${ }^{3}$ Di-galactosyl diglyceride.

${ }^{4}$ Betulinic acid, oleanolic acid, and ursolic acid were determined according to a validated in-house method; vitamin $\mathrm{C}$ and vitamin $\mathrm{E}$ were analyzed according to the official methods EN14130 and EN12822, respectively; linoleic acid, EPA, and DHA were measured according to the official method of ISO 12966-2.

${ }^{5}$ Limits of detection.

BIO-RAD Laboratories (Hercules, CA) and used in the LiquiChip Workstation IS 200 (Qiagen, Hilden, Germany) to measure the amount of secreted proteins. Data evaluation was done using the LiquiChip Analyser software (Qiagen).

2.5. Statistical Analysis. Data were evaluated by statistical tools described previously [20]. $P$ values $<0.05$ (obtained by using Student's $t$ test or one-way ANOVA) were considered to reflect statistically significant differences. Statistical differences between treatment groups were evaluated by the Student's $t$-test. Principal component analysis (PCA) was performed with the package "chemometrics" [23] of the statistical software [24] using the nipals algorithm with centered and scaled input data.

\section{Results}

3.1. Composition of $R H-A$ and $R H-B$. RH-B, prepared from rose hip fruits after removal of seeds, displayed more potent anti-inflammatory effects. The distinct biological activity of RH-A and RH-B correlated with different contents of constituents: RH-B contained higher amounts of ursolic acid, betulinic acid, GLGPG, and DHA (Table 1). Of those, ursolic acid and betulinic acid and 3-omega PUFAs, but not $\beta$-carotene, vitamin $\mathrm{C}$, or vitamin $\mathrm{E}$, displayed antiinflammatory effects (our unpublished data and $[25,26]$ ). Removal of seeds increased the contents of $\alpha$-tocopherol 
and GLGPG; the latter had anti-inflammatory properties [20]. Other constituents (e.g., vitamin C) were homogenously distributed in rose hip fruit parts.

\subsection{Effect of RH-A and RH-B on Peripheral Blood Leuko-} cytes. We investigated the effect of rose hip preparations on cells of the peripheral blood, which is an obligatory passage for nutritional supplements to the target tissue (i.e., cartilage). LPS/IFN- $\gamma$ treatment induced the secretion of large quantities of CCL2/MCP-1, CCL3/MIP-1 $\alpha$, CCL4/MIP$1 \beta$, CCL5/RANTES, CXCL10/IP-10, and CXCL8/IL-8 (Table 2 and Figure 1). Rose hip preparations significantly reduced the secretion of, for example, CCL5/RANTES, and CXCL10/IP10. Conversely, CXCL8/IL-8 and CCL3/MIP- $1 \alpha$ secretion were increased, while other chemokines (CCL11/eotaxin, CCL2/MCP-1, and CCL4/MIP-1 $\beta$ ) were not markedly altered. Similarly the secretion of interleukins and cytokines was influenced by RH preparations: IL-6 and IL-12(p70) were less produced in the presence of increasing RHP amounts, while IL-10, IL-1 $\beta$, and TNF- $\alpha$ were secreted at higher levels. The secretion of CCL5/RANTES, CXCL10/IP-10, and IL-12(p70) was influenced by the lowest tested concentration, whereas changes in others (e.g., CXCL8/IL-8, CCL3/MIP-1 $\alpha$, and IL6) required high $\mathrm{RHP}$ concentrations. $\mathrm{RH}-\mathrm{B}$ had more potent effects and thus a larger impact on inflammatory mediators than its RH-A counterpart (see Table 2). It should be mentioned that secretion of $\mathrm{PGE}_{2}$, CCL2/MCP-1, CCL4/MIP-1 $\beta$, and cytokines (e.g., IL- $1 \beta$, IL- 6 and TNF- $\alpha$ ) was stimulated by $\mathrm{RH}-\mathrm{A}$ or RH-B even in the absence of LPS/IFN- $\gamma$ (Figure 1). $\mathrm{RH}-\mathrm{A}$ and $\mathrm{RH}-\mathrm{B}$ did not impair cell viability (data not shown; see also [20]), since some of the cellular parameters were not altered by graded amount of the substances.

Next, we investigated whether RHP acted at the level of transcription or posttranscriptionally. Changes in gene expression levels showed a pattern which was similar to that of the respective proteins, as best illustrated for CXCL10/IP10, IL-6, and CXCL8/IL-8 (Table 3 and Figure 2). In comparison to RH-A, the RH-B counterpart had a stronger impact on the expression of inflammatory genes. This suggests that $\mathrm{RH}$ $\mathrm{B}$ and RH-A modulated the LPS/IFN- $\gamma$-induced changes in $\mathrm{PBL}$ at the level of transcription. One notable exception was CCL5/RANTES, which was released from activated PBL even though the respective gene activity was virtually unaltered. Also, IL-1 $\beta$ mRNA levels were decreased by RHP, whereas the cells discharged increased amounts of IL-1 $\beta$ (see Figure 1). RHP induced $\mathrm{PGE}_{2}$ in unstimulated PBL and increased it in LPS/IFN- $\gamma$-activated PBL (not shown; see also [20]). This might be explained by the presence of fatty acids that were converted into substrates for COX-1 in PBL.

3.3. Rose Hip Preparations Modulate Catabolic Gene Expression in Activated Normal Human Chondrocytes. Treatment of NHAC-kn with IL- $\beta$ drastically increased expression levels of catabolic and inflammatory genes which reflect the induction of $\mathrm{OA}$ conditions in normal chondrocytes (Table 4 and Figure 3) [12]. Within $4 \mathrm{~h}$ of stimulation, IL$1 \beta$ significantly upregulated catabolic genes (MMP-1, MMP3, MMP-13, and ADAMTS-4), cytokine genes (IL- $1 \alpha$, IL-6, and TNF- $\alpha$ ), and chemokines (CXCL8/IL-8, CCL5/RANTES, CXCL2/MIP-2, and CXCL20/MIP-3 $\alpha$ ). RH-A concentrationdependently reduced MMP-1 and MMP-3 expression by $>50 \%$, while MMP-13 expression was diminished by $90 \%$ at the highest dose of RH-A. ADAMTS-4 mRNA levels were also reduced by $\sim 50 \%$. Proinflammatory cytokine genes like IL- $1 \alpha$ and IL- 6 were significantly downregulated. With regard to chemokine genes (CXCL8/IL-8, CCL5/RANTES, CXCL2/MIP-2, and CXCL20/MIP-3 $\alpha$ ), RH-A mitigated their expression levels to a similar extent at $125-500 \mu \mathrm{g} / \mathrm{mL}$ (up to $80 \%$ reduction). $\mathrm{RH}-\mathrm{B}$ induced changes in gene expression that were comparable to those observed by RH-A, although there were quantitative differences in MMP-1, MMP-13, IL$1 \alpha$, CXCL8/IL-8, and CCL-2/MIP-2: in general, RH-B exerted weaker effects than RH-A (see "fold change" in Table 4). This is in contrast to the observations made in PBL (Table 3). Notably, CCL5/RANTES gene expression was dramatically induced in IL- $1 \beta$ treated chondrocytes, but it was not upregulated in PBL. This observation points to cell- and tissuespecific modes of action of RHP and to distinct effects of RH$\mathrm{A}$ and $\mathrm{RH}-\mathrm{B}$, respectively, in PBL and chondrocytes.

3.4. Comparison of Rose Hip Induced Changes of Variables in Different Cell Types. In order to comprehensively assess the rose hip induced changes in OA biomarkers, we performed principal component analyses (PCA). PCA is a dimension reduction method that allows transforming a complex highly correlated dataset (e.g., all OA biomarkers) into a much smaller set of uncorrelated variables, that is, principal components (PCs). In our experimental data set, the PCs were taken as "meta-biomarker" and derived in decreasing order of importance, the first PC explaining most of the variation (and thus representing most of the information) contained in the original dataset. Plotting the OA biomarkers in PCA space allows to visualize and interpret these changes, which is very difficult in the high-dimensional setting of before. Three different PCAs were run, illustrating the global effects of $\mathrm{RH}$ $A$ and RH-B on PBLs at the protein and gene level and on NHAC-kn gene level. The PCA were based on the expression of 17 PBL proteins, 10 PBL genes, and 14 NHAC-kn genes, respectively. At the protein level, LPS/IFN- $\gamma$-activated PBL were clearly separated from the LPS/IFN- $\gamma$-activated/RHPtreated cells showing a treatment effect on PC1. Additionally a concentration-dependent effect for RH-A could be observed for PC1 as well. Concentration-dependent effects for RH-B were mainly visualized by principal component 2 (Figure 4). At the gene level, LPS/IFN- $\gamma$-activated PBL were separated from higher dose LPS/IFN- $\gamma$-activated/RHPtreated cells within the first principal component. A similar clustering of treatments indicating a treatment effect was also observed within PC2. Additionally, RH-B exerted a more discriminating effect than $\mathrm{RH}-\mathrm{A}$ within PC2. The cumulative explained variability $(\mathrm{CEV})$ (explained variation of $\mathrm{PC1}+$ PC2 + PC3) for PBL at the protein and gene level was $96 \%$ and $94 \%$, respectively, with $\mathrm{PC1}$ explaining 51\% and $45 \%$ of the variability. For NHAC-kn, CEV was $94 \%$ for variations observed at the gene level $(\mathrm{PC} 1+\mathrm{PC} 2, \mathrm{PC} 1$ by itself explaining $80 \%)$. An effect of treatment was observable 

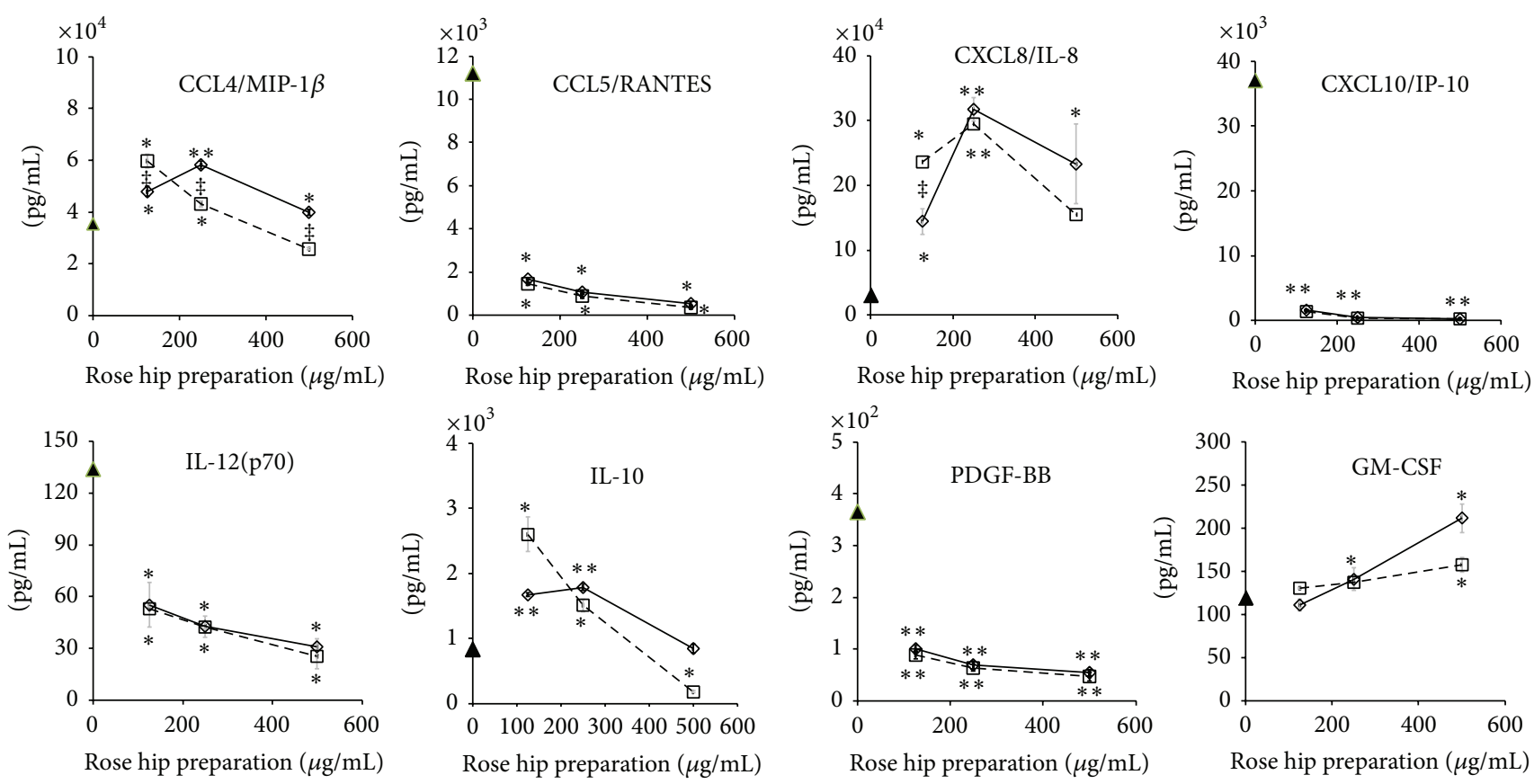

(a) Total PBLs were stimulated with LPS/IFN- $\gamma$ for $24 \mathrm{~h}$ without or with graded amounts of RH preparations. Secreted analytes were determined as detailed in Materials and Methods. Symbols on the $y$-axis indicate the amount of analytes detected on LPS/IFN- $\gamma$ only stimulated cells. Straight line: RH-A; dashed line: RH-B. ${ }^{*} P<0.05,{ }^{* *} P<0.01$ (LPS/IFN- $\gamma$ only versus LPS/IFN- $\gamma+\mathrm{RH}$ )

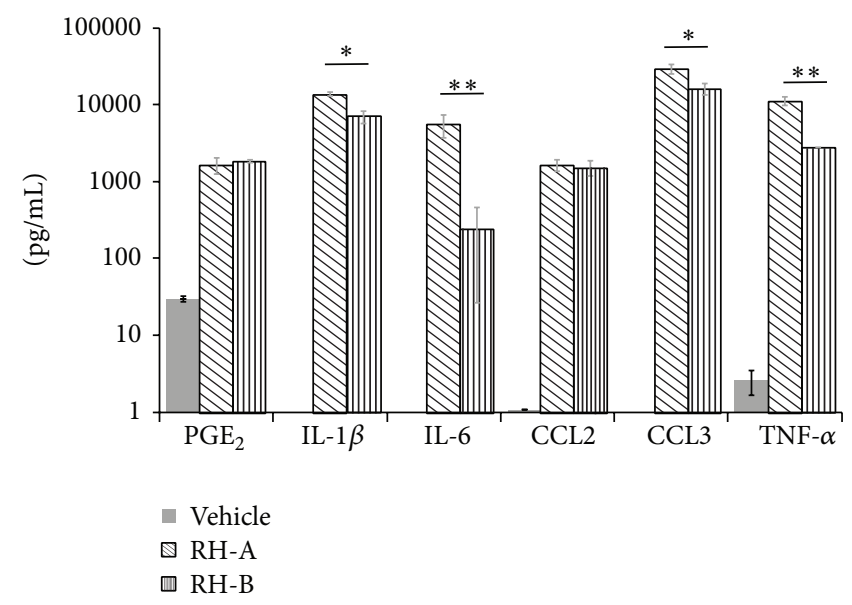

(b) Production of $\mathrm{PGE}_{2}$, various chemokines, and interleukins by unstimulated PBL. Note the logarithmic scale on the $y$-axis. RH-A and RH-B were tested at $500 \mu \mathrm{g} / \mathrm{mL} .{ }^{*} P<0.05$ and ${ }^{* *} P<0.01$ indicate the statistically significant differences between RH-A and RH-B

FIGURE 1: Effect of RH on production of $\mathrm{PGE}_{2}$ and cytokines by activated peripheral blood leukocytes.

and mostly reflected by $\mathrm{PCl}$, whereas the effect of substance concentrations (especially contrasting the high dose from the other doses) was mainly distinguished by principal component 2. A stronger effect of RH-B as compared to RHA could also be observed in PC1. Taken together, the data indicate a distinguishable and beneficial effect of $\mathrm{RH}$ on $\mathrm{OA}$ biomarkers with RH-B being a stronger discriminator than RH-A.

\section{Discussion}

In this study, a panel of biological activities of rose hip powder prepared from the whole fruit or from shells has been compared. It provides evidence that cellular features related to inflammatory responses and cartilage destruction were modulated by the complex mixture of substances contained in RHP (see Table 1). These have been measured in murine 
TABLE 2: Secretion of proteins by activated PBL. LPS/IFN- $\gamma$-stimulated cells were cultured with $125-500 \mu \mathrm{g} / \mathrm{mL}$ RHP for $24 \mathrm{~h}$ and proteins were quantified by multiparametric analysis. Only values for (LPS/IFN- $\gamma$-stimulated) cells and (500 $\mu \mathrm{g} / \mathrm{mL}$ RHP + LPS/IFN- $\gamma$-stimulated) cells are given. Differences between RH-A and RH-B are given in the right-side column.

\begin{tabular}{|c|c|c|c|c|c|c|}
\hline \multirow{2}{*}{ Protein } & \multirow{2}{*}{$\begin{array}{c}\text { LPS/IFN- } \gamma \\
\text { pg/mL } \pm \text { stdev }\end{array}$} & \multicolumn{2}{|c|}{ LPS/IFN- $\gamma+$ RH-A $(500 \mu \mathrm{g} / \mathrm{mL})$} & \multicolumn{2}{|c|}{ LPS/IFN- $\gamma+$ RH-B $(500 \mu \mathrm{g} / \mathrm{mL})$} & \multirow{2}{*}{ RH-A versus $\mathrm{RH}-\mathrm{B}$} \\
\hline & & $\mathrm{pg} / \mathrm{mL} \pm \mathrm{stdev}$ & $P$ value ${ }^{\mathrm{a}}$ & $\mathrm{pg} / \mathrm{mL} \pm \mathrm{stdev}$ & $P$ value & \\
\hline CCL11/Eotaxin & $194 \pm 7$ & $150 \pm 16$ & 0.069 & $141 \pm 15$ & 0.045 & $\mathrm{NS}^{\mathrm{b}}$ \\
\hline CCL2/MCP-1 & $1136 \pm 126$ & $1513 \pm 145$ & 0.109 & $837 \pm 106$ & 0.123 & 0.042 \\
\hline CCL3/MIP- $1 \alpha$ & $4028 \pm 513$ & $13050 \pm 919$ & 0.007 & $5455 \pm 495$ & 0.105 & 0.010 \\
\hline CCL4/MIP-1 $\beta$ & $35500 \pm 1697$ & $93875 \pm 1167$ & 0.095 & $25800 \pm 7354$ & 0.211 & 0.009 \\
\hline CXCL8/IL-8 & $30600 \pm 3253$ & $233250 \pm 61165$ & 0.042 & $155125 \pm 74635$ & 0.142 & NS \\
\hline CCL5/RANTES & $11188 \pm 1962$ & $545 \pm 91$ & 0.017 & $353 \pm 54$ & 0.016 & NS \\
\hline CXCL10/IP-10 & $37075 \pm 11208$ & $266 \pm 27$ & 0.043 & $228 \pm 35$ & 0.043 & NS \\
\hline IL-1 $\beta$ & $7165 \pm 1520$ & $37800 \pm 1980$ & 0.003 & $18550 \pm 1697$ & 0.019 & 0.021 \\
\hline IL-6 & $59975 \pm 10006$ & $47000 \pm 6293$ & 0.261 & $6525 \pm 92$ & 0.017 & 0.003 \\
\hline IL-12 (p70) & $134 \pm 17$ & $31 \pm 5$ & 0.015 & $25 \pm 7$ & 0.015 & NS \\
\hline IL-10 & $778 \pm 84$ & $845 \pm 73$ & 0.487 & $179 \pm 16$ & 0.010 & 0.010 \\
\hline TNF- $\alpha$ & $10515 \pm 474$ & $27325 \pm 3712$ & 0.024 & $6745 \pm 983$ & 0.039 & 0.044 \\
\hline GM-CSF & $113 \pm 10$ & $212 \pm 17$ & 0.018 & $158 \pm 8$ & 0.040 & NS \\
\hline G-CSF & $831 \pm 165$ & $14075 \pm 2510$ & 0.018 & $1272 \pm 16$ & 0.064 & 0.005 \\
\hline
\end{tabular}

${ }^{a} P$ value: significance value between (LPS/IFN- $\gamma$ ) and (LPS/IFN- $\gamma+$ substance) treatment.

${ }^{\mathrm{b}} \mathrm{NS}$ : not significant.

TABLE 3: Effects of RHP on gene expression in stimulated PBL (cultured for $12 \mathrm{~h}$ ). LPS/IFN- $\gamma$-stimulated cells were cultured with $125-$ $500 \mu \mathrm{g} / \mathrm{mL}$ RHP for $12 \mathrm{~h}$ and gene expression was quantified by RT-PCR. Fold changes were calculated as indicated in Materials and Methods. Values for (LPS/IFN- $\gamma$-stimulated) cells and $(500 \mu \mathrm{g} / \mathrm{mL}$ RHP + LPS/IFN- $\gamma$-stimulated) cells are given.

\begin{tabular}{|c|c|c|c|c|c|c|}
\hline \multirow{2}{*}{ Gene } & \multirow{2}{*}{$\begin{array}{l}\text { LPS/IFN- } \gamma \\
\text { Fold change }\end{array}$} & \multicolumn{2}{|c|}{ LPS/IFN- $\gamma+$ RH-A $(500 \mu \mathrm{g} / \mathrm{mL})$} & \multicolumn{2}{|c|}{ LPS/IFN- $\gamma+$ RH-B $(500 \mu \mathrm{g} / \mathrm{mL})$} & \multirow{2}{*}{ RH-A versus $\mathrm{RH}-\mathrm{B}$} \\
\hline & & Fold change & $P$ value $^{\mathrm{a}}$ & Fold change & $P$ value & \\
\hline COX-2 & 83 & 107 & 0.061 & 81 & 0.739 & $\mathrm{NS}^{\mathrm{b}}$ \\
\hline TNF- $\alpha$ & 83 & 55 & 0.006 & 42 & 0.001 & NS \\
\hline IL- $1 \alpha$ & 3513 & 1347 & $<0.001$ & 859 & $<0.001$ & NS \\
\hline IL- $1 \beta$ & 1460 & 538 & $<0.001$ & 410 & $<0.001$ & NS \\
\hline IL-6 & 15928 & 9261 & 0.058 & 3656 & $<0.001$ & 0.04 \\
\hline CCL5/RANTES & 1 & 0.8 & 0.070 & 0.8 & 0.054 & NS \\
\hline CXCL8/IL-8 & 13 & 15 & 0.418 & 28 & $<0.001$ & 0.03 \\
\hline CXCL10/IP-10 & 187 & 1 & $<0.001$ & $<\mathrm{LOD}^{\mathrm{c}}$ & $<0.001$ & Not applicable \\
\hline CXCL2/MIP-2 & 12 & 22 & 0.012 & 25 & 0.002 & NS \\
\hline CCL20/MIP-3 $\alpha$ & 3634 & 5454 & 0.014 & 6738 & 0.014 & NS \\
\hline
\end{tabular}

${ }^{a} P$ value: significance value between (LPS/IFN- $\gamma$ ) and (LPS/IFN- $\gamma+$ substance) treatment.

${ }^{b}$ NS: not significant.

${ }^{\mathrm{c}}$ Below level of detection.

and human cellular models and are fully consistent with those previously reported [20]. In LPS-activated murine macrophages RHP exhibited mainly anti-inflammatory properties including reduced production of nitric oxide, COX-2 dependent $\mathrm{PGE}_{2}$, various chemokines, and proinflammatory cytokines [20]. In PBL, the expression of interleukins and cytokines were mostly mitigated by RHP, while growth factor production like GM-CSF and G-CSF were increased. We observed a dichotomy with regard to chemokine expression: CCL5/RANTES, CCL11/eotaxin, and CXCL10/IP-10 drastically decreased, whereas others augmented in the presence of RHP (e.g., CXL8/IL-8, CCL3/MIP-1 $\alpha$, and CCL4/MIP$1 \beta)$. With regard to CCL5/RANTES and CXCL8/IL-8, their cellular release was modulated by RHP, while gene expression was not altered. Therefore, RHP could contribute to improve the amplitude and length of the acute inflammatory response through a more vigorous mobilization of lymphocytes and macrophages, while it dampens an excessive cell mobilization in chronic inflammation processes like in OA. This needs to be investigated in further experiments, where RHP should be tested on distinct subpopulations of PBL such as neutrophils, monocytes, and lymphocytes.

The pattern of observed in vitro activities was more definite in the target tissue cell equivalent, that is, chondrocytes, where gene expression of CCL5/RANTES, CXCL10/IP-10, CXCL2/MIP-2, and CCL20/MIP-3 $\alpha$ was reduced by RHP. 

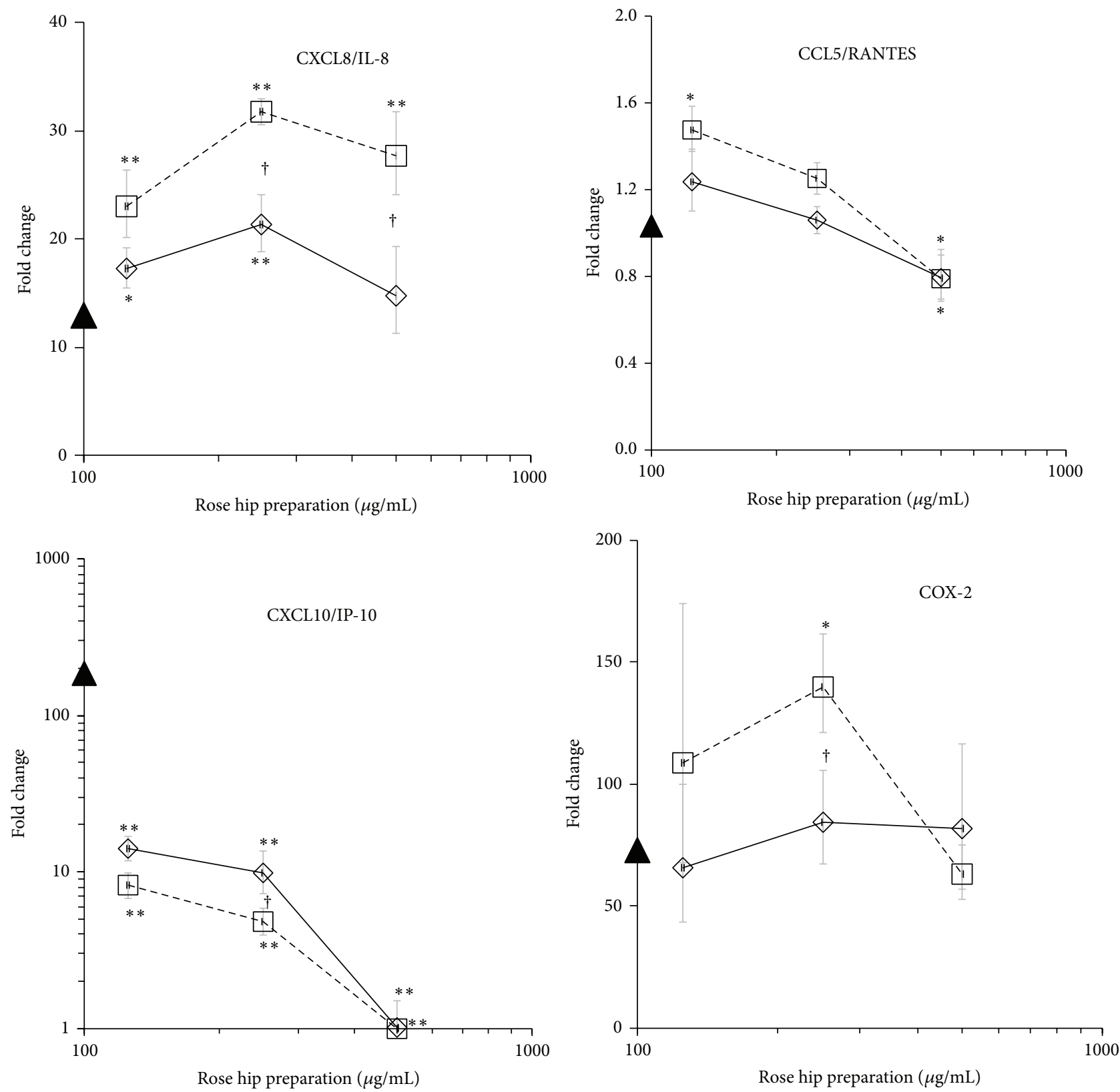

Figure 2: Effect of RH-A (straight line) and RH-B (dashed line) on gene expression in PBL. Cells were stimulated for $12 \mathrm{~h}$ with the indicated amount of substances and the gene expression was quantified by RT-PCR. Symbol on $y$-axis indicates the expression levels in LPS/IFN- $\gamma$ only stimulated PBL. ${ }^{*} P<0.05,{ }^{* *} P<0.01$ (LPS/IFN- $\gamma$ only versus LPS/IFN- $\gamma+\mathrm{RH}$ ). ${ }^{\dagger} P<0.05$ and ${ }^{\ddagger} P<0.01$ indicate the differences between RH-A and RH-B.

Concomitantly, the expression of genes that degrade ECM was diminished and thus reflected a chondroprotective effect of RHP on cartilage tissue. Previous studies highlighted the importance of chemokines in OA [27], with CCL5/RANTES and CXCL8/IL- 8 being activated in chondrocytes [9-11, 28]. Likewise, IL-1 $\beta$ activation robustly modified chemokine and chemokine receptor expression in chondrocytes [12]. The results of the present study corroborate previous data obtained with another source of RHP [20].

It is premature to unambiguously define the bioactive constituents of RH-A and $\mathrm{RH}-\mathrm{B}$, whose composition considerably differed (Table 1). Removing seeds from rose hip preparations resulted in higher contents of anti-inflammatory substances like betulinic acid, ursolic acid, galactolipids, EPA, and DHA. On the other side, seeds contained the bulk of fatty acids which could serve as substrate for inflammatory mediators such as $\mathrm{PGE}_{2}$. The multiple measured effects of RHP in different cells have been compared by PCA. These analyses demonstrated that RH-A and RH-B robustly modified a pattern or cluster of biological responses, as anticipated for beneficial effects of nutritional supplements (reviewed by, e.g., [29]). More importantly, two of the three 

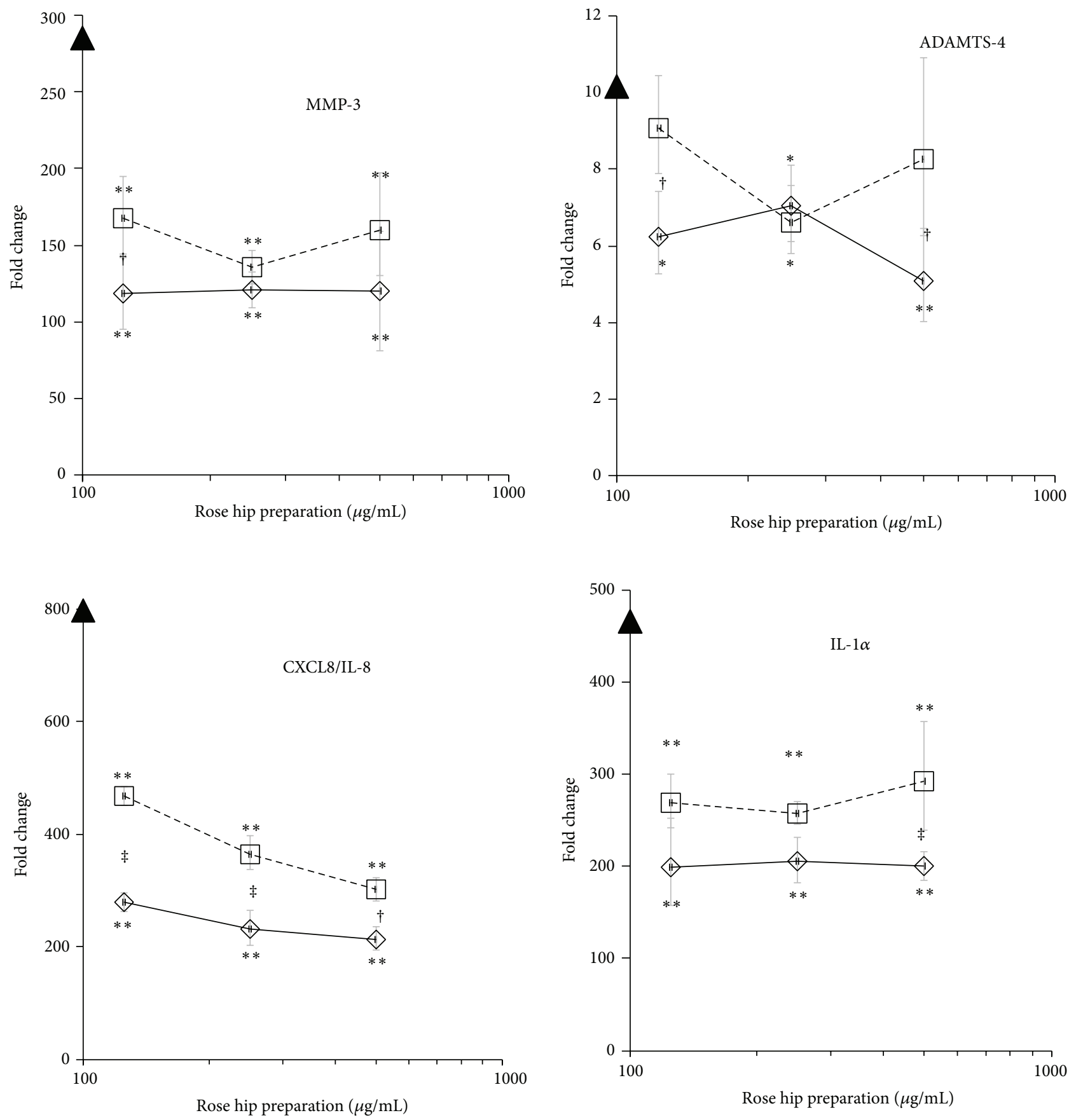

FIGURE 3: Effect of RH preparations on expression levels in human primary chondrocytes. NHAC-kn cells were stimulated with IL-1 $\beta$ for $4 \mathrm{~h}$ and the expression levels of indicated genes were quantified by RT-PCR. Triangles on $y$-axis indicate the expression levels in IL-1 $\beta$ only treated NHAC-kn. Straight line: RH-A; dashed line RH-B. ${ }^{*} P<0.05,{ }^{* *} P<0.01$ (IL- $\beta$ only versus IL- $1 \beta+\mathrm{RHP}$ ). ${ }^{\dagger} P<0.05$ and ${ }^{\ddagger} P<0.01$ indicate the differences between $\mathrm{RH}-\mathrm{A}$ and $\mathrm{RH}-\mathrm{B}$.

PCAs performed (at the level of PBL and NHAC-kn genes) showed that RH-B exhibited an overall stronger effect on OA biomarkers than RH-A. Given the demonstrated health benefit of rose hip in clinical studies (for review see, e.g., [17]), we hypothesize that in clinical studies RH-B is more efficacious or can be used in lower doses than RH-A in the treatment of OA conditions. Indeed, a recently completed randomized active-controlled trial provided evidence that, taken at half the original dose, the novel enhanced rosehip powder
(RH-B) had similar effects in patients with symptomatic OA as the original rosehip product (RH-A) [30].

\section{Conclusions}

A new form of rosehip powder has enhanced in vitro antiinflammatory and chondroprotective properties in human peripheral blood leukocytes and primary chondrocytes. 

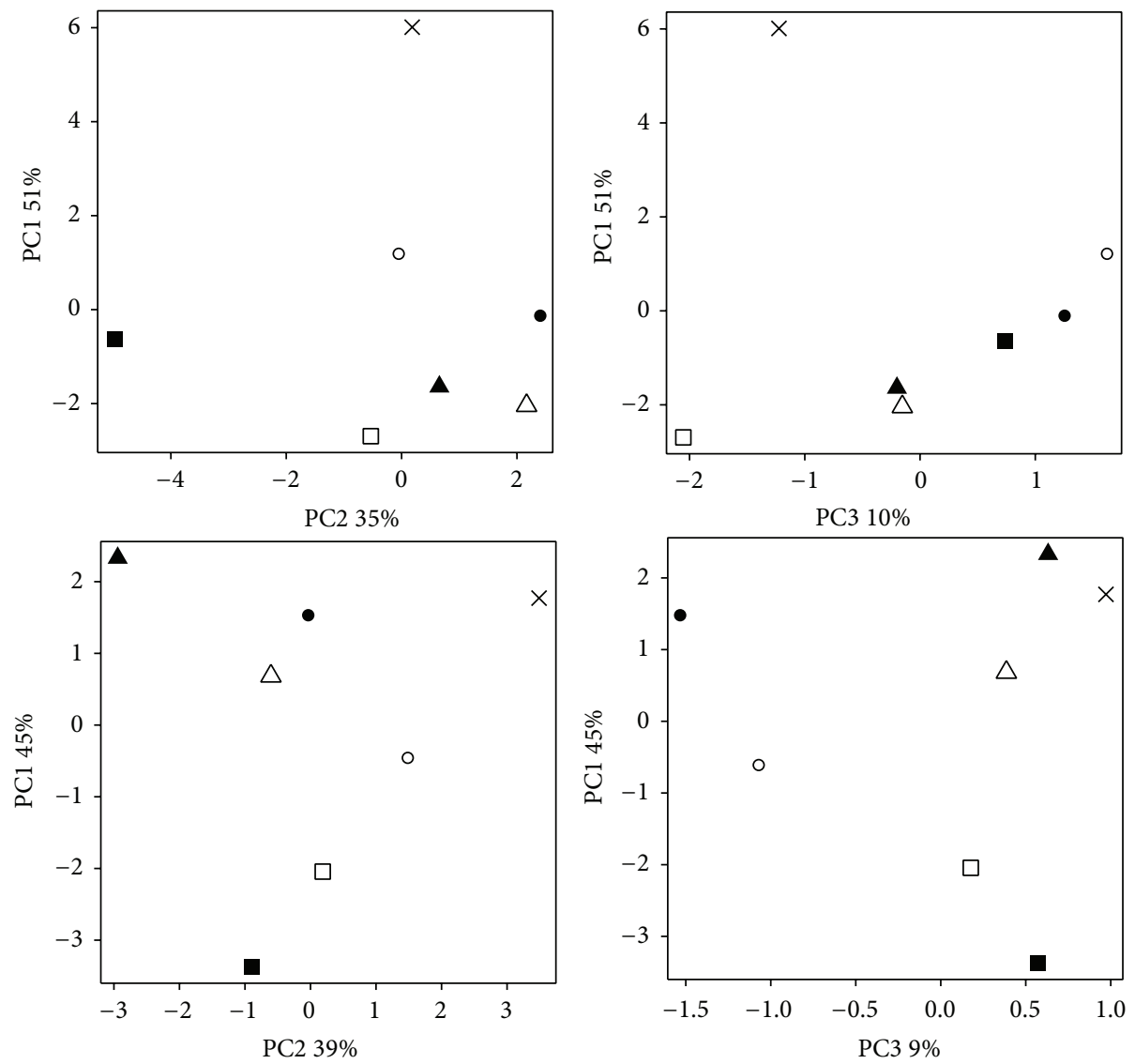
$\times$ LPS
- RHB 125
$\times$ LPS
- RHB 125
O RHA 125
A RHB 250
○ RHA 125
A RHB 250
$\triangle$ RHA 250
- RHB 500
$\triangle$ RHA 250
- RHB 500
口 RHA 500

(a) PCA of PBL proteins (upper) and genes (middle)

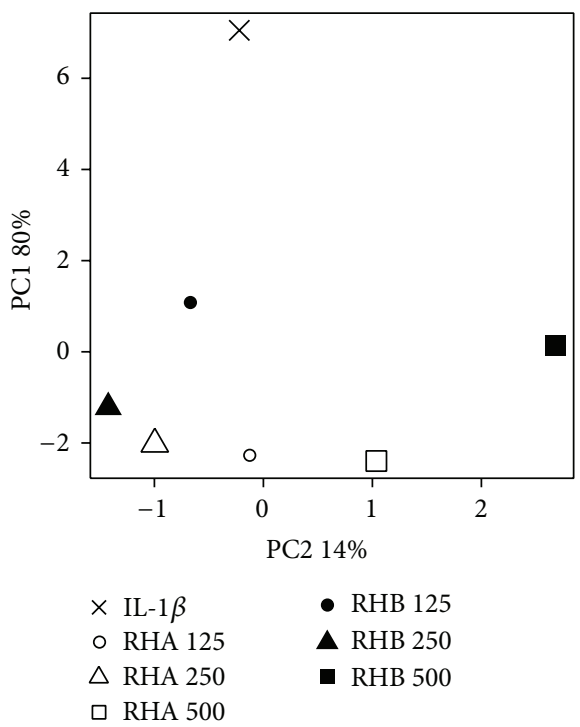

(b) PCA of NHAC-kn genes

FIGURE 4: Principal component analysis showing the impact of different treatments and concentrations of RH-A and RH-B in peripheral blood leukocytes (upper panels) and normal human chondrocytes (bottom panel). PBLs were treated with LPS/IFN- $\gamma$ alone or LPS/IFN- $\gamma$ and RHP at the indicated concentrations (in $\mu \mathrm{g} / \mathrm{mL}$ ). NHAC-kn were activated with IL-1 $\beta$ alone or IL-1 $\beta$ and RHP at the indicated concentrations. 
TABLE 4: Effects of RHP on catabolic gene expression in human primary chondrocytes. IL-1 $\beta$-stimulated cells were cultured with $125-$ $500 \mu \mathrm{g} / \mathrm{mL}$ RHP for $4 \mathrm{~h}$ and gene expression was quantified by RT-PCR. Fold changes were calculated as indicated in Materials and Methods. Values for (IL-1 $\beta$ stimulated) cells and $(500 \mu \mathrm{g} / \mathrm{mL}$ RHP + IL-1 $\beta)$ stimulated cells are given.

\begin{tabular}{|c|c|c|c|c|c|c|}
\hline \multirow{2}{*}{ Gene } & \multirow{2}{*}{$\begin{array}{c}\text { IL-1 } \beta \\
\text { Fold change }\end{array}$} & \multicolumn{2}{|c|}{$\mathrm{IL}-\beta+\mathrm{RH}-\mathrm{A}(500 \mu \mathrm{g} / \mathrm{mL})$} & \multicolumn{2}{|c|}{ IL-1 $\beta+$ RH-B $(500 \mu \mathrm{g} / \mathrm{mL})$} & \multirow{2}{*}{$\begin{array}{c}P \text { value } \\
\text { RH-A versus } \mathrm{RH}-\mathrm{B}\end{array}$} \\
\hline & & Fold change & $P$ value $^{\mathrm{a}}$ & Fold change & $P$ value & \\
\hline MMP-1 & 28 & 16 & 0.001 & 26 & 0.620 & 0.032 \\
\hline MMP-3 & 286 & 120 & 0.001 & 160 & 0.003 & $N S^{b}$ \\
\hline MMP-13 & 1.7 & 0.2 & $<0.001$ & 0.5 & $<0.001$ & 0.040 \\
\hline ADAMTS-4 & 10 & 5 & 0.006 & 8 & 0.295 & NS \\
\hline CXCL2/MIP-2 & 467 & 122 & $<0.001$ & 180 & $<0.001$ & 0.091 \\
\hline CXCL20/MIP-3 $\alpha$ & 642 & 253 & 0.001 & 331 & 0.010 & NS \\
\hline CCL5/RANTES & 176 & 127 & 0.008 & 151 & 0.241 & NS \\
\hline CXCL8/IL-8 & 797 & 214 & $<0.001$ & 301 & $<0.001$ & 0.087 \\
\hline IL- $1 \alpha$ & 466 & 200 & 0.001 & 292 & 0.032 & NS \\
\hline IL-6 & 1454 & 897 & 0.022 & 746 & 0.006 & NS \\
\hline TNF- $\alpha$ & 1120 & 1081 & 0.727 & 1704 & 0.005 & NS \\
\hline
\end{tabular}

${ }^{a} P$ values: significance value between (IL-1 $\beta$ ) and (IL-1 $\beta+$ substance) treatment.

${ }^{\mathrm{b}}$ Not significant.

\section{Abbreviations}

IL: Interleukin

LPS: Lipopolysaccharide

NO: Nitric oxide

MMP: Matrix metalloproteinase

OA: Osteoarthritis

PBL: Peripheral blood leukocytes

$\mathrm{PGE}_{2}$ : Prostaglandin $\mathrm{E}_{2}$

RH: Rose hip

RHP: Rose hip powder.

\section{Conflict of Interests}

This research was funded by Axellus Inc. and DSM Nutritional Products, where all authors are currently employed.

\section{Authors' Contribution}

Joseph Schwager and Nathalie Richard contributed equally to this work.

\section{Acknowledgments}

The authors thank J. Schierle and K. Schäfer for providing data on the rosehip composition and S. Johansen for valuable comments on the paper.

\section{References}

[1] S. R. Goldring and M. B. Goldring, "The role of cytokines in cartilage matrix degeneration in osteoarthritis," Clinical Orthopaedics and Related Research, no. 427, pp. S27-S36, 2004.

[2] J. Martel-Pelletier, C. Boileau, J.-P. Pelletier, and P. J. Roughley, "Cartilage in normal and osteoarthritis conditions," Best Practice and Research: Clinical Rheumatology, vol. 22, no. 2, pp. 351384, 2008.
[3] M. Kapoor, J. Martel-Pelletier, D. Lajeunesse, J.-P. Pelletier, and H. Fahmi, "Role of proinflammatory cytokines in the pathophysiology of osteoarthritis," Nature Reviews Rheumatology, vol. 7, no. 1, pp. 33-42, 2011.

[4] S. B. Abramson, M. Attur, A. R. Amin, and R. Clancy, "Nitric oxide and inflammatory mediators in the perpetuation of osteoarthritis," Current Rheumatology Reports, vol. 3, no. 6, pp. 535-541, 2001

[5] A. R. Amin, P. E. Di Cesare, P. Vyas et al., "The expression and regulation of nitric oxide synthase in human osteoarthritisaffected chondrocytes: evidence for up-regulated neuronal nitric oxide synthase," Journal of Experimental Medicine, vol. 182 , no. 6, pp. 2097-2102, 1995

[6] R. M. Clancy, P. F. Gomez, and S. B. Abramson, "Nitric oxide sustains nuclear factor kappaB activation in cytokinestimulated chondrocytes," Osteoarthritis and Cartilage, vol. 12, no. 7, pp. 552-558, 2004.

[7] M. B. Goldring and F. Berenbaum, "The regulation of chondrocyte function by proinflammatory mediators: prostaglandins and nitric oxide," Clinical Orthopaedics and Related Research, no. 427, pp. S37-S46, 2004.

[8] K. Vuolteenaho, T. Moilanen, R. G. Knowles, and E. Moilanen, "The role of nitric oxide in osteoarthritis," Scandinavian Journal of Rheumatology, vol. 36, no. 4, pp. 247-258, 2007.

[9] N. Alaaeddine, J. A. Di Battista, J.-P. Pelletier, K. Kiansa, J.-M. Cloutier, and J. Martel-Pelletier, "Differential effects of IL-8, LIF (pro-inflammatory) and IL-11 (anti-inflammatory) on TNF- $\alpha$ induced PGE2 release and on signalling pathways in human OA synovial fibroblasts," Cytokine, vol. 11, no. 12, pp. 1020-1030, 1999.

[10] N. Alaaeddine, T. Olee, S. Hashimoto, L. CreightonAchermann, and M. Lotz, "Production of the chemokine RANTES by articular chondrocytes and role in cartilage degradation," Arthritis \& Rheumatology, vol. 44, no. 7, pp. 1633-1643, 2001.

[11] J. I. Pulai, H. Chen, H.-J. Im et al., "NF- $\kappa$ B mediates the stimulation of cytokine and chemokine expression by human 
articular chondrocytes in response to fibronectin fragments," Journal of Immunology, vol. 174, no. 9, pp. 5781-5788, 2005.

[12] L. J. Sandell, X. Xing, C. Franz, S. Davies, L.-W. Chang, and D. Patra, "Exuberant expression of chemokine genes by adult human articular chondrocytes in response to IL-1 $\beta$," Osteoarthritis and Cartilage, vol. 16, no. 12, pp. 1560-1571, 2008.

[13] A. Kharazmi and K. Winther, "Rose hip inhibits chemotaxis and chemiluminescence of human peripheral blood neutrophils in vitro and reduces certain inflammatory parameters in vivo," Inflammopharmacology, vol. 7, no. 4, pp. 377-386, 1999.

[14] E. Larsen, A. Kharazmi, L. P. Christensen, and S. B. Christensen, "An antiinflammatory galactolipid from rose hip (Rosa canina) that inhibits chemotaxis of human peripheral blood neutrophils in vitro," Journal of Natural Products, vol. 66, no. 7, pp. 994-995, 2003.

[15] K. Winther, K. Apel, and G. Thamsborg, "A powder made from seeds and shells of a rose-hip subspecies (Rosa canina) reduces symptoms of knee and hip osteoarthritis: a randomized, doubleblind, placebo-controlled clinical trial," Scandinavian Journal of Rheumatology, vol. 34, no. 4, pp. 302-308, 2005.

[16] J. E. Chrubasik, B. D. Roufogalis, and S. Chrabasik, "Evidence of effectiveness of herbal antiinflammatory drugs in the treatment of painful osteoarthritis and chronic low back pain," Phytotherapy Research, vol. 21, no. 7, pp. 675-683, 2007.

[17] C. Chrubasik, B. D. Roufogalis, U. Müller-Ladner, and S. Chrubasik, "A systematic review on the Rosa canina effect and efficacy profiles," Phytotherapy Research, vol. 22, no. 6, pp. 725733, 2008.

[18] A. K. Jäger, I. M. S. Eldeen, and J. Van Staden, "COX-1 and -2 activity of rose hip," Phytotherapy Research, vol. 21, no. 12, pp. 1251-1252, 2007.

[19] A. K. Jäger, K. N. Petersen, G. Thomasen, and S. B. Christensen, "Isolation of linoleic and $\alpha$-linolenic acids as COX-1 and -2 inhibitors in rose hip," Phytotherapy Research, vol. 22, no. 7, pp. 982-984, 2008.

[20] J. Schwager, U. Hoeller, S. Wolfram, and N. Richard, "Rose hip and its constituent galactolipids confer cartilage protection by modulating cytokine, and chemokine expression," $B M C$ Complementary and Alternative Medicine, vol. 11, article 105, 2011.

[21] N. Richard, S. Arnold, U. Hoeller, C. Kilpert, K. Wertz, and J. Schwager, "Hydroxytyrosol is the major anti-inflammatory compound in aqueous olive extracts and impairs cytokine and chemokine production in macrophages," Planta Medica, vol. 77, no. 17, pp. 1890-1897, 2011.

[22] N. Richard, D. Porath, A. Radspieler, and J. Schwager, "Effects of resveratrol, piceatannol, triacetoxystilbene, and genistein on the inflammatory response of human peripheral blood leukocytes," Molecular Nutrition and Food Research, vol. 49, no. 5, pp. 431442, 2005.

[23] P. P. Filzmoser and K. Varmuza, "Chemometrics: Multivariate Statistical Analysis in Chemometrics," 2012, http://cran.r-project.org/web/packages/chemometrics/ index.html.

[24] A. R Core Team Vienna, Team Vienna, R: A language and environment for statistical computing, R Foundation for Statistical Computing, Vienna, Austria, 2012.

[25] B. Chakravarti, R. Maurya, J. A. Siddiqui et al., "In vitro antibreast cancer activity of ethanolic extract of Wrightia tomentosa: role of pro-apoptotic effects of oleanolic acid and urosolic acid," Journal of Ethnopharmacology, vol. 142, no. 1, pp. 72-79, 2012.
[26] V. Viji, A. Helen, and V. R. Luxmi, "Betulinic acid inhibits endotoxin-stimulated phosphorylation cascade and proinflammatory prostaglandin $\mathrm{E}_{2}$ production in human peripheral blood mononuclear cells," British Journal of Pharmacology, vol. 162, no. 6, pp. 1291-1303, 2011.

[27] G. H. Yuan, K. Masuko-Hongo, M. Sakata et al., "The role of CC chemokines and their receptors in osteoarthritis," Arthritis \& Rheumatology, vol. 44, no. 5, pp. 1056-1070, 2001.

[28] D. L. Cecil, K. Johnson, J. Rediske, M. Lotz, A. M. Schmidt, and R. Terkeltaub, "Inflammation-induced chondrocyte hypertrophy is driven by receptor for advanced glycation end products," Journal of Immunology, vol. 175, no. 12, pp. 8296-8302, 2005.

[29] P. C. Calder, N. Ahluwalia, R. Albers et al., "A consideration of biomarkers to be used for evaluation of inflammation in human nutritional studies," British Journal of Nutrition, vol. 109, supplement 1, pp. S1-S34, 2013.

[30] R. Christensen, S. Tarp, and R. Altman, "Comparing different preparations and doses of rosehip powder in patients with osteoarthritis of the knee: an exploratory randomized activecontrolled trial," International Journal of Clinical Rheumatology, vol. 21, p. S24, 2014. 


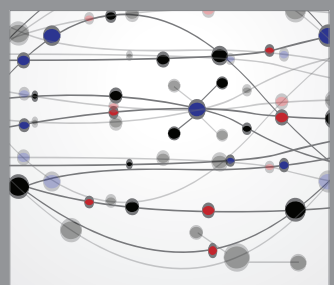

The Scientific World Journal
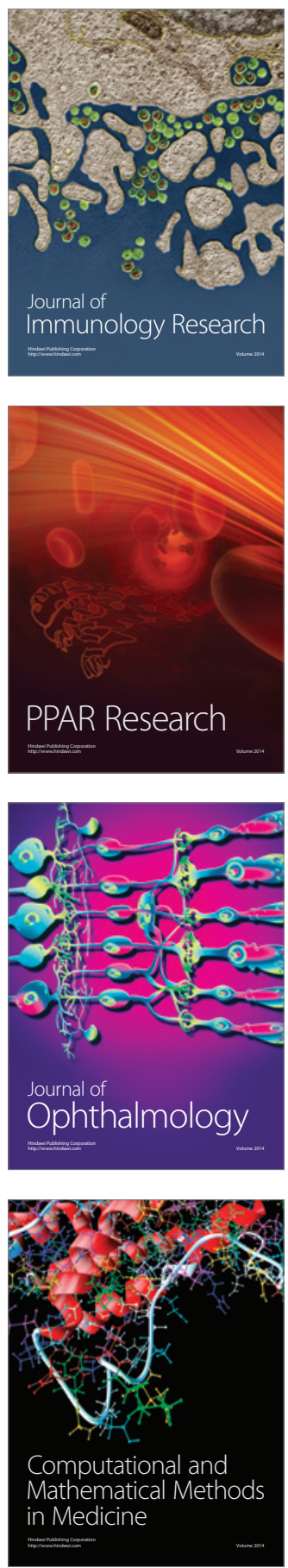

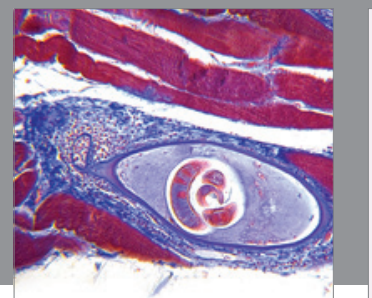

Gastroenterology

Research and Practice
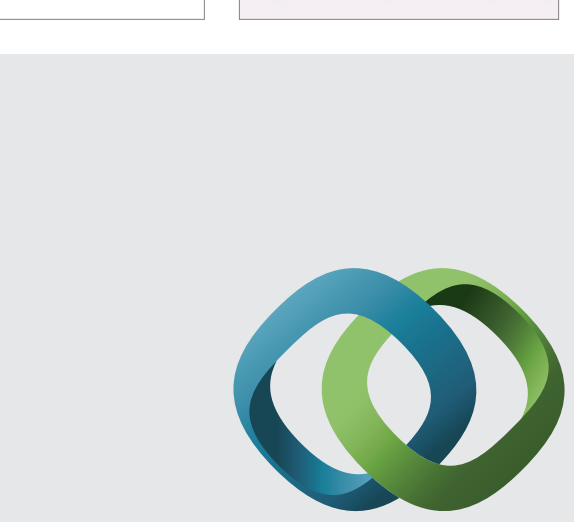

\section{Hindawi}

Submit your manuscripts at

http://www.hindawi.com
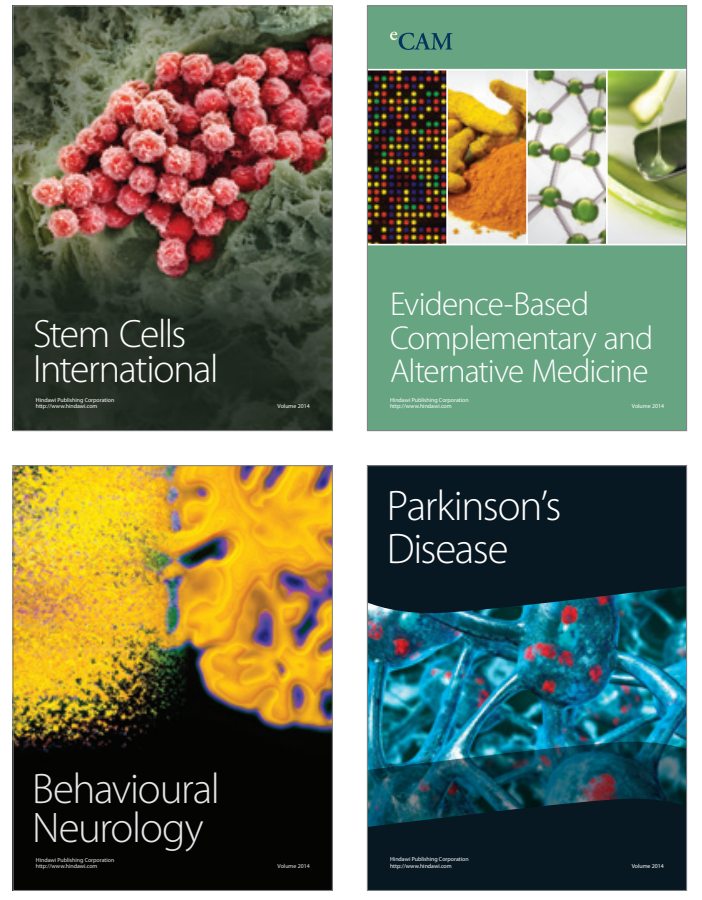
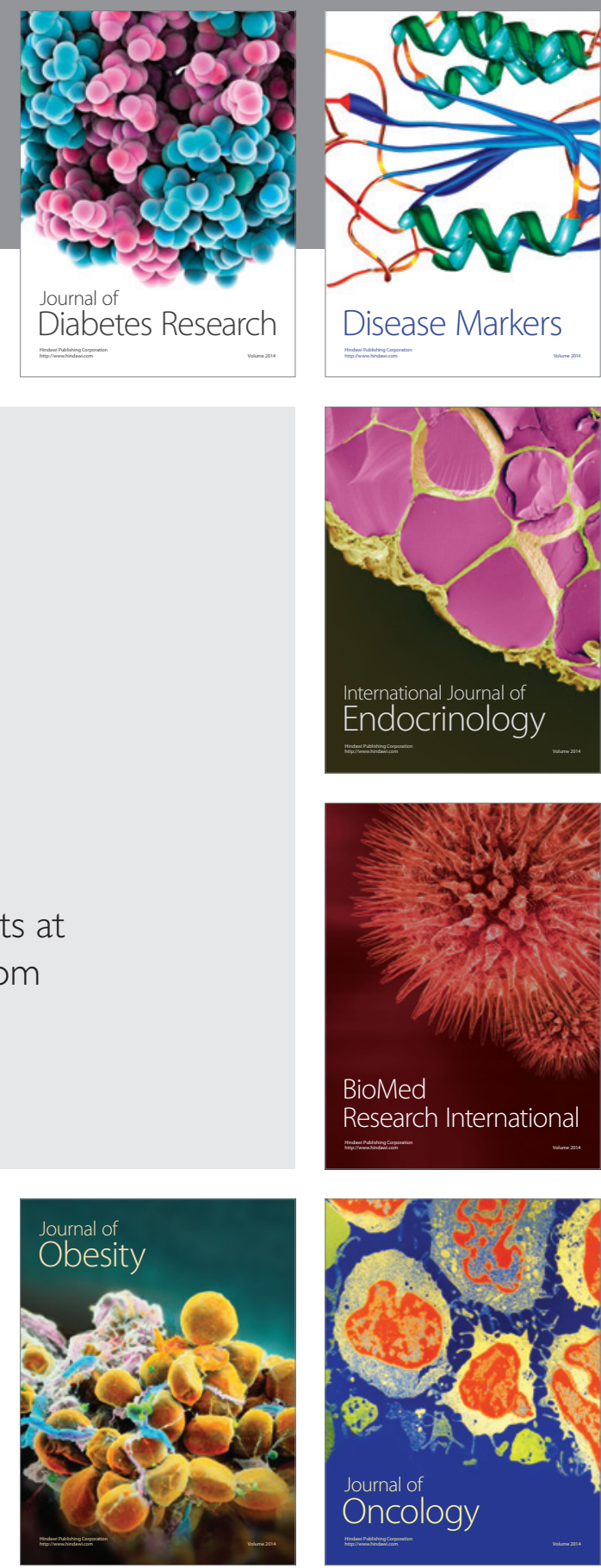

Disease Markers
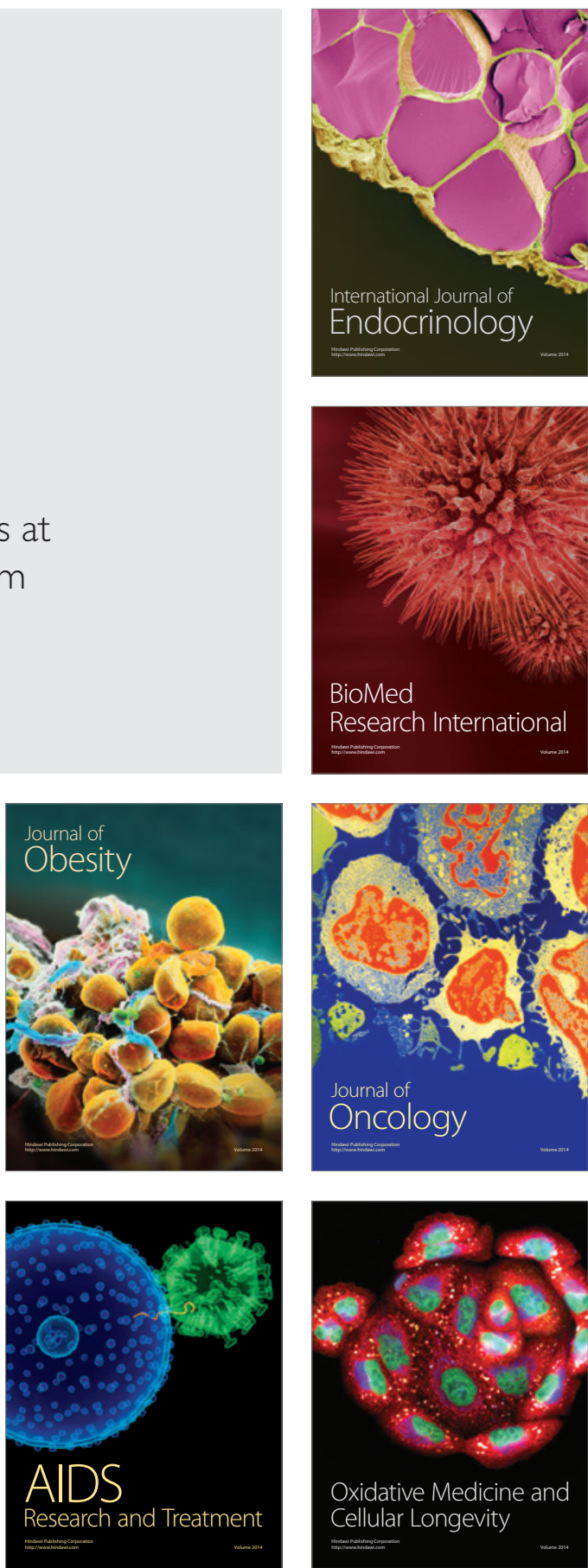